\title{
A Copper Oxide (CuO) Thin Films Deposited by Spray Pyrolysis Method
}

\author{
Youcef Bellal ${ }^{1,2, a}$, Antar Bouhank ${ }^{1}$, Hacene Serrar ${ }^{1}$, Tunç Tüken ${ }^{3}$ and Gökmen Sığırcık ${ }^{3}$ \\ ${ }^{1}$ Thin films development and applications unit Setif, Research Center in Industrial Technologies (CRTI)P.O.Box \\ 64,Cheraga 16014Algiers, Algeria \\ ${ }^{2}$ Faculty of Technology, Department of Engineering Process, Laboratory of Electrochemistry, Molecular Engineering \\ and Redox Catalysis (LEIMCR), Ferhat Abbas University Setif-1, Algeria \\ ${ }^{3}$ Faculty of Science and Letters, Çukurova University, Adana, Turkey
}

\begin{abstract}
A simple and low-cost procedure (spray pyrolysis) was used to elaborate a copper oxide thin films on ordinary glass substrates. A copper nitrate was used and dissolved in two different solutions (Water, Methanol) $S_{1}$ and $S_{2}$ respectively in order to obtain an equal concentration; $\mathrm{C}_{\mathrm{S} 1, \mathrm{~S} 2}=0.5 \mathrm{M}$. The spray pyrolysis deposition made at fixed temperature $\mathrm{T}=500^{\circ} \mathrm{C}$ and different volumes of $\mathrm{S}_{1}$ or $\mathrm{S}_{2}$ on the glass substrates. The X-ray diffraction (XRD), scanning electron microscopy (SEM) and UV-vis spectrophotometry were used to determinate the structural, morphological and optical properties of $\mathrm{CuO}$ thin films. The $\mathrm{X}$-ray diffraction patterns confirm the presence of the polycrystalline phase of $\mathrm{CuO}$ as monoclinic crystal structure with preferential orientation along (110), (002), (111), (200) and (020). Their optical band gaps ranged from 3.95 to $4.02 \mathrm{eV}$ for thin films made with $\mathrm{S}_{1}$, and from 1.6 to $1.95 \mathrm{eV}$ for thin films made with $\mathrm{S}_{2}$ with a high absorbency in the visible region, which is in agreement with the values of the literature.
\end{abstract}

\section{Introduction}

The waters pollution is an undesirable phenomenon caused by the technological development of the human being during these last centuries until the next day and which menaced the living beings to survive in this planet earth. For this, physical and / or chemical techniques are developed to fight against this serious problem [1]. In our research case we are interested in Photocatalysis, which is a simple and less expensive procedure based on the principle of activating a semiconductor using the energy provided by light. The semiconductor is considered a catalyst. Its principle is close to the heterogeneous catalysis where the oxidation-reduction reaction takes place on the surface of the catalyst [2], based on the absorption of photons with energy greater than or equal to the band gap of the photocatalyst to generate electrons in the conduction band and holes in the valence band. The electron-hole pairs thus generated can recombine or react with organic compounds adsorbed on the surface of the semiconductor via the oxidation-reduction processes. In aqueous media, the holes trap water molecules that are transformed into $\mathrm{HO}^{\circ}$ hydroxyl radicals. These hydroxyl radicals react with

\footnotetext{
${ }^{\mathrm{a}}$ Corresponding author : y.bellal@ crti.dz
} 
organic compounds in solution (photo indirect degradation). These same holes can directly oxidize organic molecules (direct photo degradation).

Photocatalysis is generated in the 1970s. This technique consists of spontaneous irradiation with daylight or an artificial lamp with a semiconductor [3]. It is considered a new active and cost-effective abatement technology for the treatment of residual organic substances and the modification of hazardous chemicals in different forms [4]. The semiconductor material undergoes radiation excitation which allows an electron of the valence band to be ejected into the conduction band [3].

In the previous years the decontamination of the undesirable (toxic) organic or mineral products found in the water is generally done by semiconductors in the form of fine particles immersed in suspensions, the regeneration and recovery of which require delicate techniques and expensive (membranes, separation column, etc. ...).

Today researchers are interested in the technique of thin films for the application of photocatalytic which involves the fixing of a thin film of a material on another material, called "substrate" whose purpose of give particular properties to the surface of the room [5]. The elaborate thin layers are generally influenced by the methods and conditions of the preparation such as the deposition technique (physical or chemical), the annealing temperature, types of substrates etc. [6]. As an example of the ultrasonic spray technique of $\mathrm{ZnO}$ films, the optoelectronic properties are largely influenced by the thickness of the film and the temperature of the substrate [7]. Above all, for a polycrystalline film, microscopic limit pores that depend on film thickness control the properties of photoconduction [7]. For a film, the thickness can be varied by the deposition time and also by the concentration of the solution. Also the temperature of the substrate that has an effect on the layer during growth.

\section{Materials and Methods}

We used in our work a simple means of deposition, it is an empty perfume spray bottle of $15 \mathrm{ml}$ volume filled with a desired precursor solution $\mathrm{S}_{1}$ or $\mathrm{S}_{2}$, a hot plate at high temperature $\left(550^{\circ} \mathrm{C}\right)$, ultra sonic apparatus, ordinary glass substrates and solvents for cleaning and preparation of $S_{1}$ and $S_{2}$ solutions. the precursor (copper nitrate ) and the solvents are Aldrich brand.

- The solutions $S_{1}$ and $S_{2}$ are prepared at room temperature under the stirring effect for one hour in the open air.

- Surface treatment of the substrates using a mixture of equimolar solvent (acetone / methanol) in an ultra sonic apparatus at $\mathrm{T}=40^{\circ} \mathrm{C}$ for 10 minutes.

\section{Results and Discussion}

\subsection{Optical Characterization}

It is well known that thin layers of $\mathrm{CuO}$ have a p-type conductivity and are the direct result of $\mathrm{Cu}$ gaps in the assembly of the structure which leads to the formation of holes in the valence bond [8]. allowed us to use equation (1) and (2) for the calculation of gap energy.

Fig.1. shows the optical absorbance spectra of thin films deposited at different solvents. As expected, the resulting $\mathrm{CuO}$ thin films exhibit: low and strong absorption in the visible region for thin films made with $S_{1}$ and $S_{2}$ respectively; however, it declines after $800 \mathrm{~nm}$ to the extent that the transparency is considerable from $900 \mathrm{~nm}$ to $1100 \mathrm{~nm}$. These are the basic characteristics of a solar selective absorber [9]. 


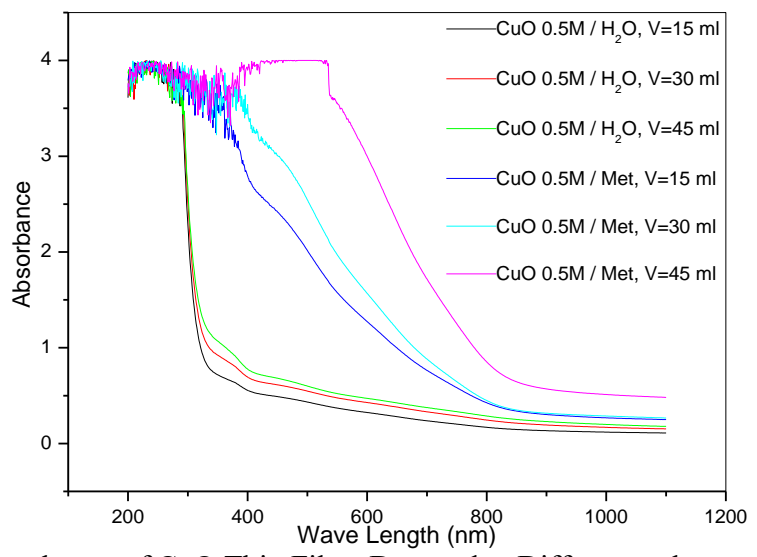

Figure. 1. Optical Absorbance of $\mathrm{CuO}$ Thin Films Deposed at Different volumes $\left(\mathrm{S}_{1}\right.$ or $\left.\mathrm{S}_{2}\right)$ at $\mathrm{T}=500^{\circ} \mathrm{C}$

In order to appreciate the gap energy of $\mathrm{CuO}$ thin films, first, the experimental data were extracted and reformed to absorption coefficient $(\alpha)$ via equation (1) [10.11] as follows:

knowing that:

$$
\alpha=\frac{1}{t} \ln \left[\frac{\left(1-R^{2}\right)}{2 T}+\sqrt{\frac{(1-R)^{4}}{4 T^{2}}}+R^{2}\right]
$$

$t$ : Thickness

$R$ : Reflectance

T: Transmittance

Taking into account that the thickness $t$ is of the order nano meter, the gap energy Eg and the absorption coefficient $\alpha$ can be calculated according to the relation of Tauc (2).

$$
\alpha h v=A\left(h v-E_{g}\right)^{n}
$$

Where $h$ is the photons energy, $A$ is an independent constant of the energy, and $\mathrm{n}$ is $1 / 2$ for the direct allowed transition. To this, the gap energy can be estimated by plotting $(\alpha h v)^{2}$ with respect to $h v$ one extrapolating the linear part of the graph at $(\alpha h v)^{2}=0$ Fig. 2 and 3 [12], whose resulting band gap values are in good agreement with the literature [13-16]. The wavelengths of the corresponding thin layers and the gap energies are mentioned in Table 1 using equation (3).

Where:

$$
E_{g}=h c / \lambda \approx 1240 / \lambda
$$

$c$ : Speed of light

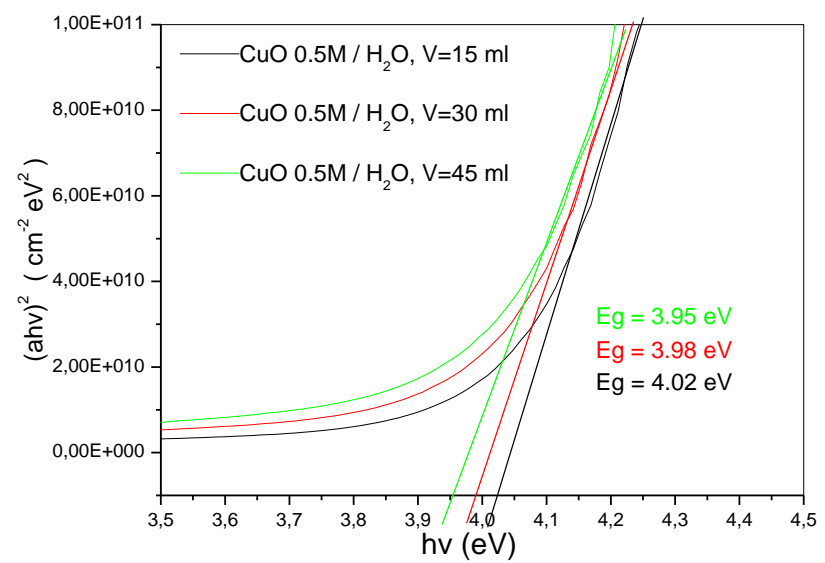

Figure. 2. Gap energy of $\mathrm{CuO}$ thin films produced at different volumes from $\mathrm{S}_{1}$ at $\mathrm{T}=500^{\circ} \mathrm{C}$. 


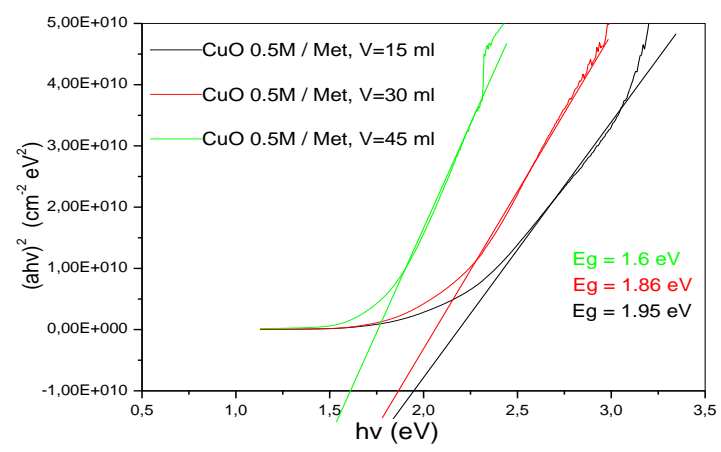

Figiure. 3. Gap energy of $\mathrm{CuO}$ thin films produced at different volumes from $\mathrm{S}_{2}$ at $\mathrm{T}=500^{\circ} \mathrm{C}$.

Table 1. The wavelength values correspond to the gap energies of the thin films elaborated by different volumes of $\mathrm{S}_{1}$ and $\mathrm{S}_{2}$ at $\mathrm{T}=500^{\circ} \mathrm{C}$.

\begin{tabular}{|c|c|c|}
\hline Sample & Energy gap (eV) & Wavelength $(\mathrm{nm})$ \\
\hline $\mathrm{CuO} 0.5 \mathrm{M} / \mathrm{H}_{2} \mathrm{O}, \mathrm{V}=15 \mathrm{ml}$ & 3.95 & 313.92 \\
\hline $\mathrm{CuO} 0.5 \mathrm{M} / \mathrm{H}_{2} \mathrm{O}, \mathrm{V}=30 \mathrm{ml}$ & 3.98 & 311.56 \\
\hline $\mathrm{CuO} 0.5 \mathrm{M} / \mathrm{H}_{2} \mathrm{O}, \mathrm{V}=45 \mathrm{ml}$ & 4.02 & 308.46 \\
\hline $\mathrm{CuO} 0.5 \mathrm{M} / \mathrm{Met}, \mathrm{V}=15 \mathrm{ml}$ & 1.6 & 775.00 \\
\hline $\mathrm{CuO} 0.5 \mathrm{M} / \mathrm{Met}, \mathrm{V}=30 \mathrm{ml}$ & 1.86 & 666.66 \\
\hline $\mathrm{CuO} 0.5 \mathrm{M} / \mathrm{Met}, \mathrm{V}=45 \mathrm{ml}$ & 1.95 & 635.89 \\
\hline
\end{tabular}

It seems that among the factors that can possibly modify the gap energy is the size of the crystallites of the $\mathrm{CuO}$ thin films which are mainly responsible for the band gap variation. In this study, the correlation between crystallite size and band gap was discussed earlier [17,18]. As a result, by decreasing the size of the crystallites by changing the polarity of the solvent towards the less polar, the band gap has generally increased.

\subsection{Structural Characterization}

\subsubsection{XRD Characterization}

The X-ray diffraction diagrams (fig. 4) of the $\mathrm{CuO}$ thin films produced at different volumes of $\mathrm{S}_{1}$ or $\mathrm{S}_{2}$ at $\mathrm{T}=500^{\circ} \mathrm{C}$. show a high intensity of peaks observed at $2 \theta=35.55^{\circ}$ and $38.73^{\circ}$ to the diffraction planes (002) and (111) and some small peaks assigned to (110), (200), (-202), (020), (202), (-113), ($311),(220))$ and (311) observed at $2 \theta=32.52 .41 .98,48.74,53.68,58.30,61.56,66.25,68.13$ and $72.34^{\circ}$, respectively. It can be noticed that the XRD model has not changed much by the precursor solvent change. All the apparent atomic planes show the formation of the $\mathrm{CuO}$ phase with monoclinic crystalline structure. The diffraction peaks (002) and (111) of $\mathrm{CuO}$ were high in the process of increasing the thickness of the thin layer due to the increase in precursor concentration [19].

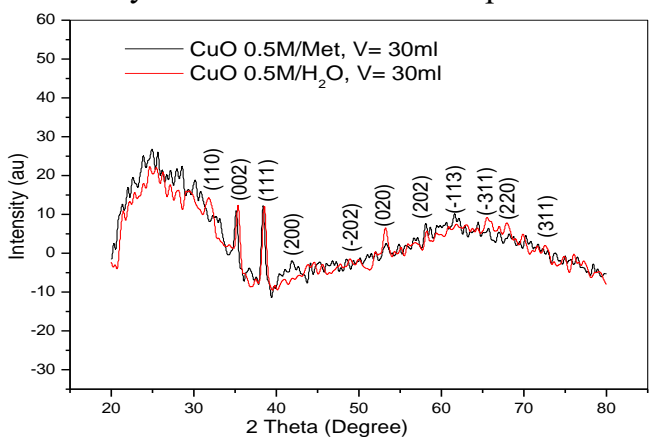

Figure. 4. X-ray diffraction of $\mathrm{CuO}$ thin films made at different solvents $\mathrm{S}_{1}$ or $\mathrm{S}_{2}$ at $\mathrm{V}=30 \mathrm{ml}$ and $\mathrm{T}=500^{\circ} \mathrm{C}$. 


\subsubsection{SEM Characterization}

Two surface morphologies of the thin films produced with different solvents (water or methanol) were observed. Spherical grains tightly packaged with different sizes from 40 to $160 \mathrm{~nm}$ in diameter for thin films made with $\mathrm{S}_{1}$ [20]. Well-bonded and overlapped coral-shaped grains are observed for thin layers made with $\mathrm{S}_{2}$ (Fig. 5).
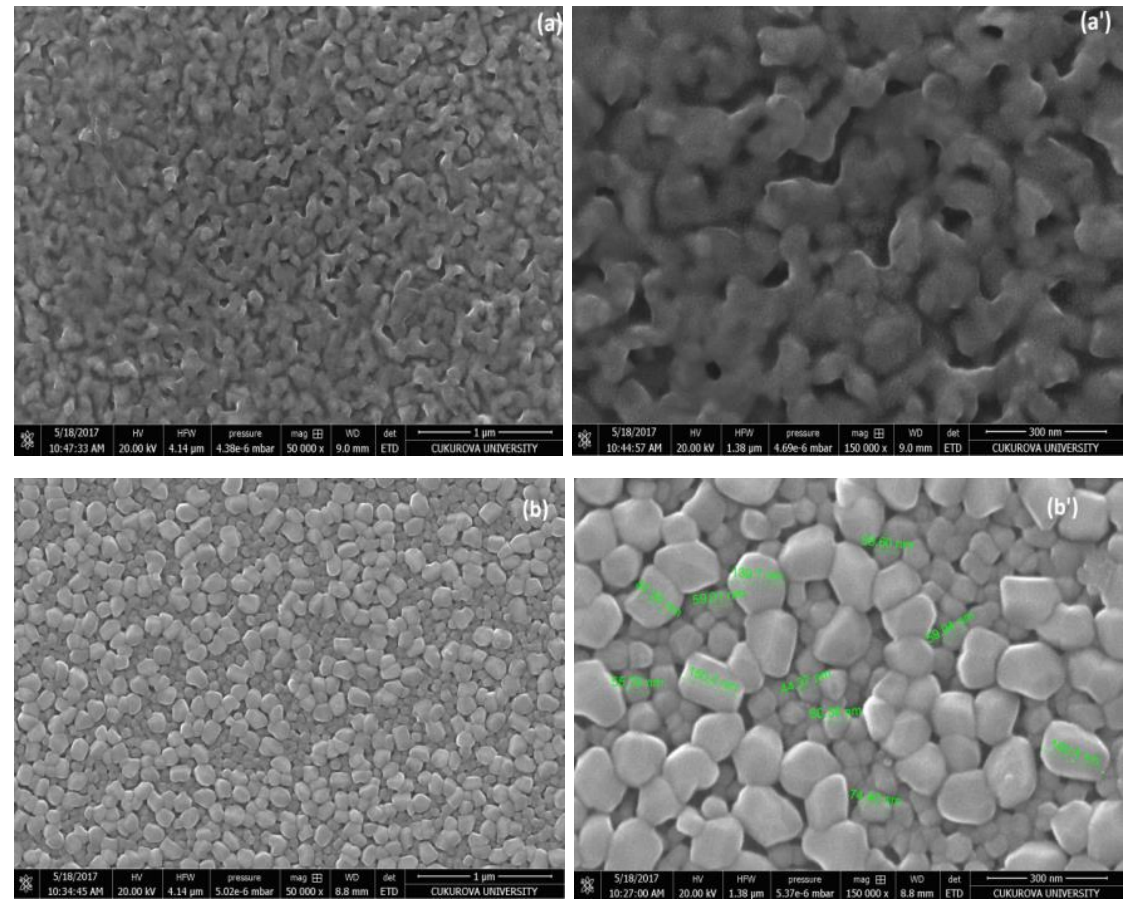

Figure. 5. SEM images at $\mathrm{T}=500^{\circ} \mathrm{C}, \mathrm{V}=30 \mathrm{ml}$ : a, a '(CuO/Methanol), b, b' $\left(\mathrm{CuO} / \mathrm{H}_{2} \mathrm{O}\right)$.

\section{Conclusions}

The thin films obtained by the spray pyrolysis method using the copper nitrate precursor us to conclude the following results:

$>$ The speed and the affordable cost of the technique.

> The UV-Visible characterization showed that all films exhibit ultraviolet optical transmission and their optical band gaps ranged from 3.95 to $4.02 \mathrm{eV}$ for thin films made with $\mathrm{S}_{1}$, and from 1.6 to $1.95 \mathrm{eV}$ for thin films made with $\mathrm{S}_{2}$.

$>$ The X-ray diffraction patterns confirm the presence of the polycrystalline phase of $\mathrm{CuO}$ as monoclinic crystal structure.

$>$ SEM images show that a material $(\mathrm{CuO})$ settles differently on the surface of substrates by noticing a homogeneous roughness and nanoscale grains with high wettability for $\mathrm{CuO}$ deposited with $S_{2}$ unlike $S_{1}$. so this roughness is a very positive factor for the photo-catalytic degradation phenomenon.

\section{Acknowledgements}

The authors gratefully acknowledge the financial support from the Algerian Ministry of Higher

Education and Scientific Research. The authors would like to thank Professor 
Abderrahmane Bouabellou, Thin Films and Interfaces Laboratory, Frere Mentouri University, Constantine, Algeria, for helpful.

\section{References}

1. V. Kazpard, Z. Saad, A.-G. El Samrani et K. Slim. European journal of water quality - Journal européen d'hydrologie, 10, p. 71-77, 2005.

2. Vincent Felisab. Claude De Bellefonb. Pierre Fouillouxb. Daniel Schweichb. Applied Catalysis B: Environmental..20. p. 91-100, 1999.

3. Atef A., Elaboration De $\mathrm{TiO} 2$ Sous Forme De Couche Mince Dopée Et Nanotubulaire : Caractérisation Électrochimique Et Performance Photocatalytique. Thése de Doctorat, Université El Manar,Tunisie, 132, 2013

4. Ahmed S., Rasul M., Martens W.N., Richard B., Hashib M. A., Advances in Heterogeneous Photocatalytic

Degradation of Phenols and Dyes in Wastewater: A Review, 27, 2010.

5. Xingwang Z, Minghua Z, Lecheng L, Mater. Chem. Phys. p. 73-79, 2005.

6. K. Zine Ali, Thèse de magister, Université Houari Boumediene Alger, 2003.

7. Ayadi Meriem, Thèse de magister Université de Skikda, 2006.

8. Jeong YK, Choi GM. Journal of Physics and Chemistry of Solids. 57(1), p. 81-84, 1996.

9. Shabu R, Raj AME, Sanjeeviraja C, Ravidhas C..Materials Research Bulletin. 68:18, 2015.

10. Yahia IS, Farag AAM, El-Faify S, Yakuphanoglu F, Al-GhamdiAA.. International Journal for Light and Electron Optics.127(3), p. 1429-1433, 2016.

11. Hassanien AS, Akl AA.. Superlattices and Microstructures.89, p. 153-169, 2016.

12. Tauc J, Grigorovici R, Vancu A..physica status solidi (b).15(2), p. 627-637, 1966.

13. Saravanan V, Shankar P, Mani GK, Rayappan JBB.. Journal of Analytical and Applied Pyrolysis.111, p. 272-277, 2015.

14. Kose S, Atay F, Bilgin V, Akyuz I. Materials Chemistry and Physics. 111(2-3), p. 351-358, 2008.

15. Mehdi Dhaouadi et al., American Journal of Physics and Applications, 6(2),p. 43-50, 2018.

16. M. Lamri Zeggar et al., International Journal of Physical and Mathematical Sciences, 9(10), p. 632-635, 2015.

17. Akgul FA, Akgul G, Yildirim N, Unalan HE, Turan R.. Materials Chemistry and Physics., 147(3), p. 987-995, 2014.

18. Gupta Y, Arun P, Naudi AA, Walz MV, Albanesi EA, Thin Solid Films, 612, p. 310-316, 2016.

19. R. Shabu, A. Moses Ezhil Raj, C. Sanjeeviraja, C. Ravidhas, Materials Research, Bulletin, 68, p. $1-8,2015$.

20. P.Venkateswari,P. Thirunavukkarasua, M. Ramamurthy, M. Balaji, J. Chandrasekaran, International Journal for Light and Electron Optics, S0030-4026(17)30434-5, 2017. 